- of the processes involved could improve projections of future climate change.

SOCCOM, which launched in 2014, has funding from the US National Science Foundation to operate in the Southern Ocean for six years. Project scientists' ultimate goal is to expand to all the world's oceans. That would require roughly 1,000 floats, and would cost an estimated \$25 million per year.

Interest in this global array, dubbed the Biogeochemical Argo, is growing. The Japanese government has put a proposal to expand use of SOCCOM probes on the agenda for the meetings of the Group of 7 leading industrialized nations in Japan in May. And the project is gaining high-level attention as a result: the SOCCOM team has briefed John Holdren, science adviser to US President Barack Obama.

Project scientists are rushing to develop a plan to expand use of the next-generation probes. "It's like, 'Oh, couldn't they wait a year?'” jokes SOCCOM associate director Ken Johnson, an ocean chemist at the Monterey Bay Aquarium Research Institute in Moss Landing, California. His team is drafting a proposal to present to the international Argo steering committee at a meeting that begins on 22 March.

Meanwhile, another set of researchers hopes to extend the existing Argo array beyond its current 2,000-metre limit. The US National Oceanic and Atmospheric Administration (NOAA) is spending about $\$ 1$ million annually on a Deep Argo project to monitor ocean temperature and salinity down to 6,000 metres. The agency deployed nine Deep Argo floats south of New Zealand in

\section{DIVING DEEPER}

Roughly 3,900 Argo floats monitor conditions in the upper oceans. Now, scientists hope to go deeper to cover $99 \%$ of Earth's seawater.

Temperature, pressure and salinity data transmitted to waiting satellite

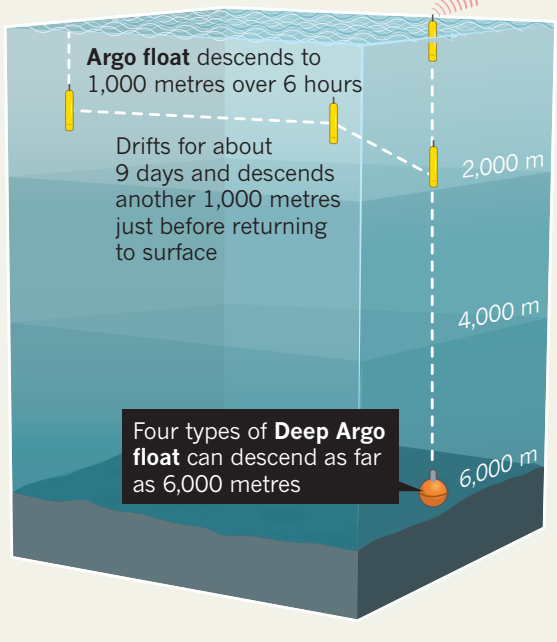

January, and is planning similar pilot arrays in the Indian Ocean and the North Atlantic.

The deep-ocean data will be particularly useful in improving how models simulate ocean circulation, says Alicia Karspeck, an ocean modeller at the National Center for Atmospheric Research in Boulder, Colorado. "From a scientific perspective, it's a no-brainer," she says - noting that the new floats are a low-risk investment compared with spending money on developing models without additional oceanographic data.
NOAA is using two different models of float, both designed to withstand the crushing pressures at the bottom of the sea. And Argo teams in Japan and Europe are already using upgraded floats that can reach down to 4,000 metres. The goal is to establish a new international array of some 1,250 deep-ocean floats - most of which would need to dive to 6,000 metres. Doing so would provide basic data on $99 \%$ of the world's seawater.

"We are really still working the bugs out of the equipment and trying to show that we can do this," says Gregory Johnson, a NOAA oceanographer in Seattle, Washington, and one of the principal investigators for Deep Argo.

Even if scientists succeed in expanding nextgeneration ocean probes around the globe, he says, the data that they provide will not supplant detailed measurements of carbon, water chemistry, salinity and temperature that are currently made by ship-based surveys. Deep Argo measures only temperature and salinity, and the technology used in Biogeochemical Argo is not yet sensitive enough to measure subtle changes in the deep ocean.

Still, ship surveys - which are done on average every ten years - cannot follow how heat is taken up by the deep ocean. By contrast, Deep Argo would allow researchers to continually watch heat move through the oceans. That could lead to a better understanding of how the oceans respond to global warming - and how the climate responds to the oceans.

"This has all kinds of ramifications for ecosystems and climate," says Johnson of NOAA.

TECHNOLOGY

Mobile-phone health apps
deliver data bounty

Smartphone programs allow researchers to recruit large numbers of participants and monitor them in real time.

\section{BY ERIKA CHECK HAYDEN}

$\mathrm{L}$ ast summer, physician Yvonne Chan wondered how the wildfires raging through Washington state were affecting people with asthma - for whom smoke and heat can trigger breathing difficulties. So she tapped into data collected through the Asthma Health iPhone app, which 8,700 people with asthma use each day to record their symptoms and triggers. Chan found that when fires flared up, so did asthma symptoms and reports of environmental triggers among users living near the blazes.

"In the past, stuff like this was just logistically impossible to do," says Chan, director of digital health at the Icahn Institute for Genomics and Multiscale Biology at Mount Sinai in New York City. "It opens up a brand-new area of research."
Smartphone apps developed by academics, pharmaceutical companies and technology giants are making possible large studies that collect real-time data on people's location, environment and health. Last March, for example, Apple debuted its ResearchKit developer tools. Scientists and companies have used these tools to make iPhone apps targeted to specific conditions.

Researchers are only now gaining access to 
of these mobile-collected data sets, but the scope of such programs is expanding: on $21 \mathrm{March}$, Apple announced that ResearchKit apps can now import a user's genetic data from the consumer testing service 23 andMe, based in Mountain View, California. Chan's asthma app and MyHeartCounts, a cardiovasculardisease app developed by Stanford University in California, will be the first to be able to easily incorporate users' 23 andMe data, if participants allow it.

“The biggest thing we're likely to get with these apps is scale," says neuroscientist James Beck, vice-president for scientific affairs at the Parkinson's Disease Foundation in New York City. mPower, a ResearchKit app that is aimed at people with Parkinson's disease, has enrolled more than 6,800 participants -3 times the number in the largest previous Parkinson's study.

Collecting health data through an app also makes it easy to share them with other researchers. The mPower and asthma apps ask users whether they would like to make their data available for further analyses. So far, most have agreed $-75 \%$ with mPower and $90 \%$ in the asthma study. On 3 March, roughly one year after mPower launched, it released a data set from its users - a huge departure from the past, when it would have taken years to collect and distribute such a large amount of data.

"One of the things I like about these new digital ways of gathering information is that it's an opportunity to have data-sharing enabled by the trial itself," says Stephen Friend, president of Sage Bionetworks, a non-profit organization in Seattle, Washington, that developed mPower.

Still, many researchers are taking a waitand-see approach to the new technology. ResearchKit launched last year with 5 apps; there are now 25, tracking conditions including autism, breast cancer and multiple sclerosis. Some are surprised that more scientists haven't developed their own apps: “I'm shocked to see that we're a year into this and there's so few apps in there," says Atul Butte, director of the Institute for Computational Health Sciences at the University of California, San Francisco.

Some may be wary about the quality of the data collected by mobile apps; in many of the ResearchKit studies, study personnel do not

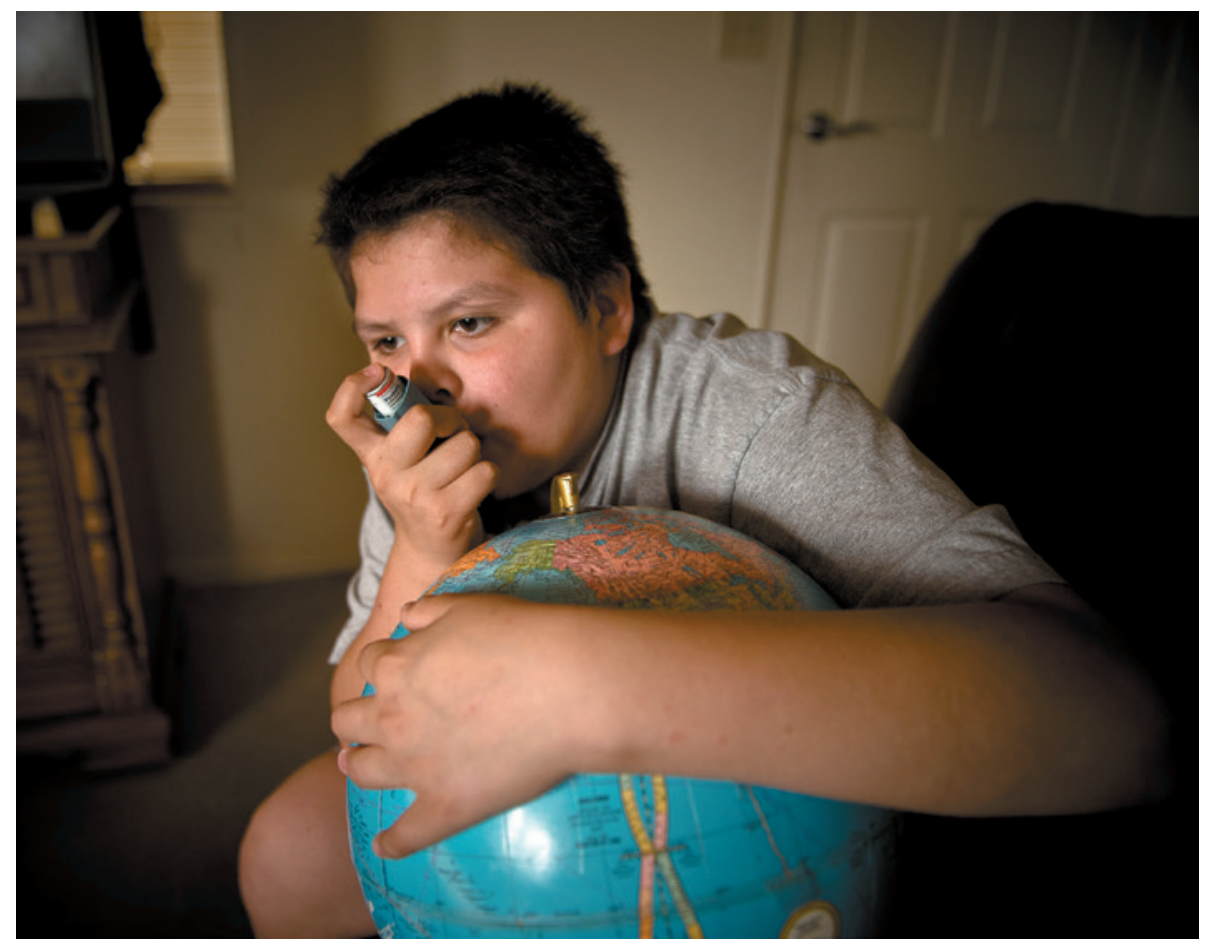

Almost 9,000 people with asthma use a smartphone app daily to record their symptoms and triggers.

meet participants, raising questions about the quality of the data that these participants provide. With this in mind, researchers are working to spot-check their app data. Chan's team has examined whether the height and gender of the asthma-app users correlate as expected with peak flow, a measurement of breathing ability that is usually higher for men

\section{"We're just at the edge of this wave."} and for taller people. So far, that relationship has held up. "We don't have participants randomly

\section{entering bad data," Chan says.}

But whether research apps can keep users engaged over the long term is an open question. For instance, mPower uses the iPhone's accelerometer and microphone to measure the steadiness of participants' gait and speech, respectively. But only about 1,000 mPower participants have elected to fill out a survey that assesses cognitive function.

"There's a drop-off in interest as things get more difficult to do," Beck says. "There needs to be some value to the user, so that people don't pick it up and play with it for the first hour and never go back to it."

Friend agrees. His company is working on making the mPower app more user-friendly. "When we look back on it, we'll probably go, 'Wow, this is clunky'," he says of the current app.

And researchers are still working out how best to use the data from such programs. Because participants' data are collected in real time and much more often than usual - for example, daily, as opposed to during a quarterly visit to a physician's surgery - one logical application is in clinical trials of therapeutics. Pharmaceutical company Roche, based in Basel, Switzerland, has developed a Parkinson's app that it is using in a study of a new drug.

Others suggest that mobile-enabled research may eventually lead to wearable devices that automatically collect information about participants in real time - such as those being developed by Verily in Mountain View. Its Baseline Study will use wearable devices to collect user data, with the aim of gaining insights into how to detect and prevent disease.

Says Beck: "We're just at the edge of this wave."

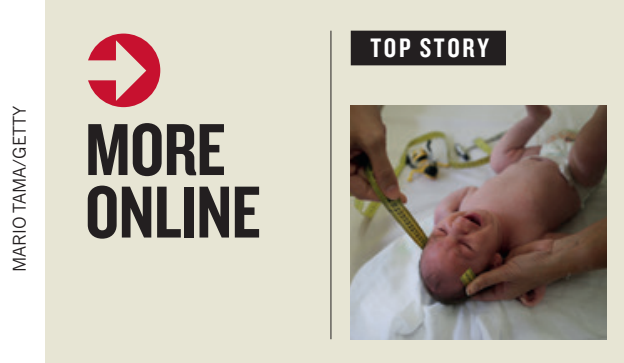

The Zika virus and birth defects: what we know and what we don't go.nature.com/ jylflc

\section{MORE NEWS}

- GM zebrafish forms technicolour 'skinbow' go.nature.com/7toog9

- Australian cryptologists

concerned by restrictive exports law go.nature.com/f3qtcu

- Dengue vaccine aces trailblazing trial go.nature.com/ai607c

\section{NATURE PODCAST}

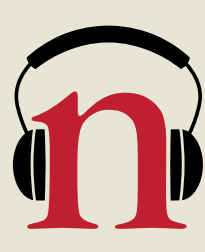

Toggling brains with radio waves; building stuff that lasts; and thrillseeking rodents nature.com/nature/ podcast 